\title{
Coupled coincidence point results for a generalized compatible pair with applications
}

\author{
Nawab Hussain ${ }^{1}$, Mujahid Abbas², ${ }^{2}$ Akbar Azam³ $^{3}$ and Jamshaid Ahmad ${ }^{3}$
}

"Correspondence:

mujahid.abbas@up.ac.za

${ }^{2}$ Department of Mathematics and

Applied Mathematics, University of

Pretoria, Lynwood Road, Pretoria,

002, South Africa

Full list of author information is

available at the end of the article

\begin{abstract}
In this paper, employing a new concept of generalized compatibility of a pair of mappings defined on a product space, certain coupled coincidence point results of mappings involved herein are obtained. We also deduce certain coupled fixed point results without mixed monotone property of $F$. Our results generalize some recent comparable results in the literature. Moreover, some examples and an application to integral equations are given here to illustrate the usability of the obtained results.
\end{abstract}

MSC: $46 \mathrm{~S} 40 ; 47 \mathrm{H} 10 ; 54 \mathrm{H} 25$

Keywords: coupled coincidence point; generalized compatibility; mixed monotone property; ordered set; complete metric space

\section{Introduction}

The existence of fixed points in ordered metric spaces has been investigated by Ran and Reurings [1]. Recently, many researchers have obtained fixed point and coupled fixed point results in partially ordered metrics spaces (see, e.g., [2-16]).

The study of coupled fixed points in partially ordered metric spaces was initiated by Guo and Lakshmikantham [17], and then attracted many researchers, see for example [1820] and references therein. Bhaskar and Lakshmikantham [21] introduced the notions of mixed monotone mapping and coupled fixed point. As an application, they studied the existence and uniqueness of a solution for a periodic boundary value problem associated with a first order ordinary differential equation. Lakshmikantham and Cirić in [22] introduced the concepts of coupled coincidence and coupled common fixed point for mappings satisfying nonlinear contractive conditions in partially ordered complete metric spaces and generalized the concept of the mixed monotone property. For more on coupled fixed point theory we refer to the reviews (see, e.g. [4, 23-33]). Recently, Alotaibi and Alsulami [34] presented some coupled coincidence point results involving the $(\phi, \psi)$-contractive condition for mappings having the mixed $g$-monotone property in a partially ordered metric space which are generalizations of the results of Luong and Thuan [35].

In this paper, we introduce the notion of generalized compatibility of a pair $\{F, G\}$, of mappings $F, G: X \times X \rightarrow X$. We then employ this notion to obtain coupled coincidence point results for such a pair of mappings involving $(\phi, \psi)$-contractive condition without mixed $G$-monotone property of $F$. Thus the derived coupled fixed point results do not have the mixed monotone property of $F$. Our results represent new versions of the results of Alotaibi and Alsulami [34], Luong and Thuan [35] and Bhaskar and Lakshmikantham 
[21]. We also provide an example and an application to an integral equation to support our results presented here.

\section{Preliminaries}

We now recall some basic definitions and important results for our use in the sequel.

Definition 1 [21] Let $(X, \preceq)$ be a partially ordered set. The mapping $F: X \times X \rightarrow X$ is said to have the mixed monotone property if $F$ is monotone non-decreasing in its first argument and is monotone non-increasing in its second argument, that is, for all $x_{1}, x_{2} \in$ $X, x_{1} \preceq x_{2}$ implies $F\left(x_{1}, y\right) \preceq F\left(x_{2}, y\right)$, for any $y \in X$ and for all $y_{1}, y_{2} \in X, y_{1} \preceq y_{2}$ implies $F\left(x, y_{1}\right) \succeq F\left(x, y_{2}\right)$, for any $x \in X$.

Lakshmikantham and Ćirić [22] generalized the concept of a mixed monotone property as follows.

Definition 2 [22] Let $(X, \preceq)$ be a partially ordered set and $g$ a self mapping on $X$. A mapping $F: X \times X \rightarrow X$ is said to have the mixed $g$-monotone property if for all $x_{1}, x_{2} \in X$, $g x_{1} \preceq g x_{2}$ implies that $F\left(x_{1}, y\right) \preceq F\left(x_{2}, y\right)$, for any $y \in X$ and for all $y_{1}, y_{2} \in X, g y_{1} \preceq g y_{2}$ implies that $F\left(x, y_{1}\right) \succeq F\left(x, y_{2}\right)$, for any $x \in X$.

Definition 3 [22] An element $(x, y) \in X \times X$ is called a coupled coincidence point of the mappings $F: X \times X \rightarrow X$ and $g: X \rightarrow X$ if $F(x, y)=g x$ and $F(y, x)=g y$.

Definition 4 [22] Let $X$ be a nonempty set, $g$ a self mapping on $X$ and $F: X \times X \rightarrow X$ and $g: X \rightarrow X$. We say that $F$ and $g$ are commutative if $g(F(x, y))=F(g x, g y)$, for all $x, y \in X$.

Definition 5 [26] Let $(X, d)$ be a metric space, $F: X \times X \rightarrow X$ a mapping and $g$ a self mapping on $X$. A hybrid pair $F, g$ is compatible if

$$
\lim _{n \rightarrow+\infty} d\left(g\left(F\left(x_{n}, y_{n}\right)\right), F\left(g x_{n}, g y_{n}\right)\right)=0
$$

and

$$
\lim _{n \rightarrow+\infty} d\left(g\left(F\left(y_{n}, x_{n}\right)\right), F\left(g y_{n}, g x_{n}\right)\right)=0
$$

whenever $\left\{x_{n}\right\}$ and $\left\{y_{n}\right\}$ are sequences in $X$, such that

$$
\lim _{n \rightarrow+\infty} F\left(x_{n}, y_{n}\right)=\lim _{n \rightarrow+\infty} g x_{n}=x \text { and } \lim _{n \rightarrow+\infty} F\left(y_{n}, x_{n}\right)=\lim _{n \rightarrow+\infty} g y_{n}=y
$$

with $x, y \in X$.

As given in $[34,35], \Phi$ denotes the set of all functions $\phi:[0, \infty) \rightarrow[0, \infty)$ such that:

1. $\phi$ is continuous and increasing,

2. $\phi(t)=0$ if and only if $t=0$,

3. $\phi(t+s) \leq \phi(t)+\phi(s)$, for all $t, s \in[0,+\infty)$.

Let $\Psi$ be the set of all the functions $\psi:[0, \infty) \rightarrow[0, \infty)$ such that $\lim _{t \rightarrow r} \psi(t)>0$ for all $r>0$ and $\lim _{t \rightarrow 0^{+}} \psi(t)=0$. 
The main result in [34] is given by the next theorem.

Theorem 6 Let $(X, \preceq)$ be a partially ordered set and suppose there is a metric d on $X$ such that $(X, d)$ is a complete metric space. Let $F: X \times X \rightarrow X$ be a mapping having the $g$-mixed monotone property on $X$ such that there exist two elements $x_{0}, y_{0} \in X$ with

$$
g x_{0} \preceq F\left(x_{0}, y_{0}\right) \text { and } g y_{0} \succeq F\left(y_{0}, x_{0}\right) \text {. }
$$

Suppose there exist $\phi \in \Phi$ and $\psi \in \Psi$ such that

$$
\phi(d(F(x, y), F(u, v))) \leq \frac{1}{2} \phi(d(g x, g u)+d(g y, g v))-\psi\left(\frac{d(g x, g u)+d(g y, g v)}{2}\right)
$$

for all $x, y, u, v \in X$, with $g x \succeq g u$ and $g y \preceq g v$. Suppose $F(X \times X) \subseteq g(X), g$ is continuous and compatible with $F$ and also suppose either

(a) $F$ is continuous or

(b) $X$ has the following property:

(i) if a non-decreasing sequence $\left\{x_{n}\right\} \rightarrow x$, then $x_{n} \preceq x$ for all $n$,

(ii) if a non-decreasing sequence $\left\{y_{n}\right\} \rightarrow y$, then $y_{n} \preceq y$ for all $n$.

Then there exist $x, y \in X$ such that $g(x)=F(x, y)$ and $g(y)=F(y, x)$, that is, $F$ and $g$ have a coupled coincidence point in $X$.

Definition 7 Suppose that $F, G: X \times X \rightarrow X$ are two mappings. $F$ is said to be $G$-increasing with respect to $\preceq$ if for all $x, y, u, v \in X$, with $G(x, y) \preceq G(u, v)$ we have $F(x, y) \preceq F(u, v)$.

Example 8 Let $X=(0, \infty)$ be endowed with the natural ordering of real numbers $\leq$. Define mappings $F, G: X \times X \rightarrow X$ by $F(x, y)=\ln (x+y)$ and $G(x, y)=x+y$ for all $(x, y) \in X \times X$. Note that $F$ is $G$-increasing with respect to $\leq$.

Example 9 Let $X=\mathbb{N}$ endowed with the partial order $\preceq$ defined by $x, y \in X \times X, x \preceq y$ if and only if $y$ divides $x$. Define the mappings $F, G: X \times X \rightarrow X$ by $F(x, y)=x^{2} y^{2}$ and $G(x, y)=x y$ for all $(x, y) \in X \times X$. Then $F$ is $G$-increasing with respect to $\preceq$.

Definition 10 An element $(x, y) \in X \times X$ is called a coupled coincidence point of mappings $F, G: X \times X \rightarrow X$ if $F(x, y)=G(x, y)$ and $F(y, x)=G(y, x)$.

Example 11 Let $F, G: \mathbb{R} \times \mathbb{R} \rightarrow \mathbb{R}$ be defined by $F(x, y)=x y$ and $G(x, y)=\frac{2}{3}(x+y)$ for all $(x, y) \in X \times X$. Note that $(0,0),(1,2)$, and $(2,1)$ are a coupled coincidence points of $F$ and $G$.

Definition 12 Let $F, G: X \times X \rightarrow X$. We say that the pair $\{F, G\}$ is generalized compatible if

$$
\left\{\begin{array}{l}
d\left(F\left(G\left(x_{n}, y_{n}\right), G\left(y_{n}, x_{n}\right)\right), G\left(F\left(x_{n}, y_{n}\right), F\left(y_{n}, x_{n}\right)\right)\right) \rightarrow 0 \quad \text { as } n \rightarrow+\infty \\
d\left(F\left(G\left(y_{n}, x_{n}\right), G\left(x_{n}, y_{n}\right)\right), G\left(F\left(y_{n}, x_{n}\right), F\left(x_{n}, y_{n}\right)\right)\right) \rightarrow 0 \text { as } n \rightarrow+\infty
\end{array}\right.
$$

whenever $\left(x_{n}\right)$ and $\left(y_{n}\right)$ are sequences in $X$ such that

$$
\left\{\begin{array}{l}
\lim _{n \rightarrow \infty} F\left(x_{n}, y_{n}\right)=\lim _{n \rightarrow \infty} G\left(x_{n}, y_{n}\right)=t_{1}, \\
\lim _{n \rightarrow \infty} F\left(y_{n}, x_{n}\right)=\lim _{n \rightarrow \infty} G\left(y_{n}, x_{n}\right)=t_{2} .
\end{array}\right.
$$


Example 13 Let $(\mathbb{R},|\cdot|)$ be a usual metric space. Define mappings $F, G: X \times X \rightarrow X$ by $F(x, y)=x^{2}-y^{2}$ and $G(x, y)=x^{2}+y^{2}$ for all $x, y \in X$. Let $\left(x_{n}\right)$ and $\left(y_{n}\right)$ be two sequences in $X$ such that

$$
\left\{\begin{array}{l}
F\left(x_{n}, y_{n}\right) \rightarrow t_{1} G\left(x_{n}, y_{n}\right) \rightarrow t_{1} \quad \text { as } n \rightarrow+\infty \\
F\left(x_{n}, y_{n}\right) \rightarrow t_{2} G\left(x_{n}, y_{n}\right) \rightarrow t_{2} \quad \text { as } n \rightarrow+\infty
\end{array}\right.
$$

We can prove easily that $t_{1}=t_{2}=0$ and

$$
\left\{\begin{array}{l}
d\left(F\left(G\left(x_{n}, y_{n}\right), G\left(y_{n}, x_{n}\right)\right), G\left(F\left(x_{n}, y_{n}\right), F\left(y_{n}, x_{n}\right)\right)\right) \rightarrow 0 \quad \text { as } n \rightarrow+\infty \\
d\left(F\left(G\left(y_{n}, x_{n}\right), G\left(x_{n}, y_{n}\right)\right), G\left(F\left(y_{n}, x_{n}\right), F\left(x_{n}, y_{n}\right)\right)\right) \rightarrow 0 \quad \text { as } n \rightarrow+\infty .
\end{array}\right.
$$

Thus the pair $\{F, G\}$ satisfies the generalized compatibility.

Definition 14 Let $F, G: X \times X \rightarrow X$ be two maps. We say that the pair $\{F, G\}$ is commuting if

$$
F(G(x, y), G(y, x))=G(F(x, y), F(y, x))
$$

for all $x, y \in X$.

Obviously, a commuting pair is a generalized compatible but not conversely in general.

\section{Main results}

Now we prove our main result.

Theorem 15 Let $(X, \preceq)$ be a partially ordered set such that there exists a complete metric $d$ on $X$. Assume that $F, G: X \times X \rightarrow X$ are two generalized compatible mappings such that $F$ is G-increasing with respect to $\preceq, G$ is continuous and has the mixed monotone property, and there exist two elements $x_{0}, y_{0} \in X$ with

$$
G\left(x_{0}, y_{0}\right) \preceq F\left(x_{0}, y_{0}\right) \quad \text { and } \quad G\left(y_{0}, x_{0}\right) \succeq F\left(y_{0}, x_{0}\right) \text {. }
$$

Suppose that there exist $\phi \in \Phi$ and $\psi \in \Psi$ such that

$$
\begin{aligned}
\phi(d(F(x, y), F(u, v))) \leq & \frac{1}{2} \phi(d(G(x, y), G(u, v))+d(G(y, x), G(v, u))) \\
& -\psi\left(\frac{d(G(x, y), G(u, v))+d(G(y, x), G(v, u))}{2}\right)
\end{aligned}
$$

for all $x, y, u, v \in X$, with $G(x, y) \preceq G(u, v)$ and $G(y, x) \succeq G(v, u)$. Suppose that for any $x, y \in$ $X$, there exist $u, v \in X$ such that

$$
\left\{\begin{array}{l}
F(x, y)=G(u, v) \\
F(y, x)=G(v, u) .
\end{array}\right.
$$

Also suppose that either

(a) F is continuous or 
(b) $X$ has the following properties:

(i) if a non-decreasing sequence $\left\{x_{n}\right\} \rightarrow x$, then $x_{n} \preceq x$ for all $n$,

(ii) if a non-increasing sequence $\left\{y_{n}\right\} \rightarrow y$, then $y \leq y_{n}$ for all $n$.

Then $F$ and $G$ have a coupled coincidence point in $X$.

Proof Let $x_{0}, y_{0} \in X$ be such that $G\left(x_{0}, y_{0}\right) \preceq F\left(x_{0}, y_{0}\right)$ and $F\left(y_{0}, x_{0}\right) \preceq G\left(y_{0}, x_{0}\right)$ (such points exist by hypothesis). From (3.2), there exists $\left(x_{1}, y_{1}\right) \in X \times X$ such that $F\left(x_{0}, y_{0}\right)=G\left(x_{1}, y_{1}\right)$ and $F\left(y_{0}, x_{0}\right)=G\left(y_{1}, x_{1}\right)$. Continuing this process, we can construct two sequences $\left\{x_{n}\right\}$ and $\left\{y_{n}\right\}$ in $X$ such that

$$
F\left(x_{n}, y_{n}\right)=G\left(x_{n+1}, y_{n+1}\right), F\left(y_{n}, x_{n}\right)=G\left(y_{n+1}, x_{n+1}\right) \quad \text { for all } n \in \mathbb{N} \text {. }
$$

First we show that for all $n \in \mathbb{N}$, we have

$$
G\left(x_{n}, y_{n}\right) \preceq G\left(x_{n+1}, y_{n+1}\right) \quad \text { and } \quad G\left(y_{n+1}, x_{n+1}\right) \preceq G\left(y_{n}, x_{n}\right)
$$

As $G\left(x_{0}, y_{0}\right) \preceq F\left(x_{0}, y_{0}\right)$ and $F\left(y_{0}, x_{0}\right) \preceq G\left(y_{0}, x_{0}\right)$ and as $F\left(x_{0}, y_{0}\right)=G\left(x_{1}, y_{1}\right)$ and $F\left(y_{0}, x_{0}\right)=$ $G\left(y_{1}, x_{1}\right)$, we have $G\left(x_{0}, y_{0}\right) \preceq G\left(x_{1}, y_{1}\right)$ and $G\left(y_{1}, x_{1}\right) \preceq G\left(y_{0}, x_{0}\right)$. Thus (3.4) holds for $n=0$. Suppose now that (3.4) holds for some fixed $n \in \mathbb{N}$. Since $F$ is $G$-increasing with respect to $\preceq$, we have

$$
G\left(x_{n+1}, y_{n+1}\right)=F\left(x_{n}, y_{n}\right) \preceq F\left(x_{n+1}, y_{n+1}\right)=G\left(x_{n+2}, y_{n+2}\right)
$$

and

$$
G\left(y_{n+2}, x_{n+2}\right)=F\left(y_{n+1}, x_{n+1}\right) \preceq F\left(y_{n}, x_{n}\right)=G\left(y_{n+1}, x_{n+1}\right) .
$$

Hence (3.4) holds for all $n \in \mathbb{N}$. For all $n \in \mathbb{N}$, denote

$$
\delta_{n}=d\left(G\left(x_{n}, y_{n}\right), G\left(x_{n+1}, y_{n+1}\right)\right)+d\left(G\left(y_{n}, x_{n}\right), G\left(y_{n+1}, x_{n+1}\right)\right) .
$$

We can suppose that $\delta_{n}>0$ for all $n \in \mathbb{N}$. If not, $\left(x_{n}, y_{n}\right)$ will be a coincidence point and the proof is finished. We claim that for any $n \in \mathbb{N}$, we have

$$
\phi\left(\delta_{n+1}\right) \leq \phi\left(\delta_{n}\right) .
$$

Since $G\left(x_{n}, y_{n}\right) \preceq G\left(x_{n+1}, y_{n+1}\right)$ and $G\left(y_{n}, x_{n}\right) \succeq G\left(y_{n+1}, x_{n+1}\right)$, letting $x=x_{n}, y=y_{n}, u=x_{n+1}$ and $v=y_{n+1}$ in (3.1) and using (3.3), we get

$$
\begin{aligned}
\phi( & \left.d\left(G\left(x_{n+1}, y_{n+1}\right), G\left(x_{n+2}, y_{n+2}\right)\right)\right) \\
= & \phi\left(d\left(F\left(x_{n}, y_{n}\right), F\left(x_{n+1}, y_{n+1}\right)\right)\right) \\
\leq & \frac{1}{2} \phi\left(d\left(G\left(x_{n}, y_{n}\right), G\left(x_{n+1}, y_{n+1}\right)\right)+d\left(G\left(y_{n}, x_{n}\right), G\left(y_{n+1}, x_{n+1}\right)\right)\right) \\
& -\psi\left(\frac{d\left(G\left(x_{n}, y_{n}\right), G\left(x_{n+1}, y_{n+1}\right)\right)+d\left(G\left(y_{n}, x_{n}\right), G\left(y_{n+1}, x_{n+1}\right)\right)}{2}\right) \\
= & \frac{1}{2} \phi\left(\delta_{n}\right)-\psi\left(\frac{\delta_{n}}{2}\right) .
\end{aligned}
$$


Similarly we have

$$
\begin{aligned}
\phi( & \left.d\left(G\left(y_{n+2}, x_{n+2}\right), G\left(y_{n+1}, x_{n+1}\right)\right)\right) \\
= & \phi\left(d\left(F\left(y_{n+1}, x_{n+1}\right), F\left(y_{n}, x_{n}\right)\right)\right) \\
\leq & \frac{1}{2} \phi\left(d\left(G\left(y_{n+1}, x_{n+1}\right), G\left(y_{n}, x_{n}\right)\right)+d\left(G\left(x_{n+1}, y_{n+1}\right), G\left(x_{n}, y_{n}\right)\right)\right) \\
& \quad-\psi\left(\frac{d\left(G\left(y_{n+1}, x_{n+1}\right), G\left(y_{n}, x_{n}\right)\right)+d\left(G\left(x_{n+1}, y_{n+1}\right), G\left(x_{n}, y_{n}\right)\right)}{2}\right) \\
= & \frac{1}{2} \phi\left(\delta_{n}\right)-\psi\left(\frac{\delta_{n}}{2}\right) .
\end{aligned}
$$

Summing (3.7) and (3.8), we obtain

$$
\phi\left(\delta_{n+1}\right) \leq \phi\left(\delta_{n}\right)-2 \psi\left(\frac{\delta_{n}}{2}\right)
$$

Since $\phi$ is non-decreasing, it follows that the sequence $\left(\delta_{n}\right)$ is monotone decreasing. Therefore, there is some $\delta \geq 0$ such that $\lim _{n \rightarrow+\infty} \delta_{n}=\delta^{+}$. We shall show that $\delta=0$. Assume on contrary that $\delta>0$. Then taking the limit as $n \rightarrow+\infty$ (equivalently, $\delta_{n} \rightarrow \delta$ ) in (3.9), using the fact that $\lim _{n \rightarrow r} \psi(t)>0$ for all $r>0$ and $\phi$ is continuous, we have

$$
\begin{aligned}
\phi(\delta) & =\lim _{n \rightarrow+\infty} \phi\left(\delta_{n}\right) \leq \lim _{n \rightarrow+\infty}\left[\phi\left(\delta_{n-1}\right)-2 \psi\left(\frac{\delta_{n-1}}{2}\right)\right] \\
& =\phi(\delta)-2 \lim _{\delta_{n-1} \rightarrow \delta} \psi\left(\frac{\delta_{n-1}}{2}\right)<\phi(\delta)
\end{aligned}
$$

a contradiction. Thus $\delta=0$, that is

$$
\begin{aligned}
& \lim _{n \rightarrow+\infty}\left[d\left(G\left(x_{n}, y_{n}\right), G\left(x_{n+1}, y_{n+1}\right)\right)+d\left(G\left(y_{n}, x_{n}\right), G\left(y_{n+1}, x_{n+1}\right)\right)\right] \\
& \quad=\lim _{n \rightarrow+\infty} \phi\left(\delta_{n}\right)=0 .
\end{aligned}
$$

We shall prove that $\left(G\left(x_{n}, y_{n}\right), G\left(y_{n}, x_{n}\right)\right)$ is a Cauchy sequence in $X \times X$ endowed with the metric $\Lambda$ defined by $\Lambda((x, y),(u, v))=d(x, u)+d(y, v)$ for all $(x, y),(u, v) \in X \times X$. If $\left(G\left(x_{n}, y_{n}\right), G\left(y_{n}, x_{n}\right)\right)$ is not a Cauchy sequence in $(X \times X, \Lambda)$. Then there exists $\varepsilon>0$ for which we can find two sequences of positive integers $(m(k))$ and $(n(k))$ such that for all positive integer $k$ with $n(k)>m(k)>k$, we have

$$
\left\{\begin{array}{l}
\Lambda\left(\left(G\left(x_{m(k)}, y_{m(k)}\right), G\left(y_{m(k)}, x_{m(k)}\right)\right),\left(G\left(x_{n(k)}, y_{n(k)}\right), G\left(y_{n(k)}, x_{n(k)}\right)\right)\right)>\varepsilon \\
\Lambda\left(\left(G\left(x_{m(k)}, y_{m(k)}\right), G\left(y_{m(k)}, x_{m(k)}\right)\right),\left(G\left(x_{n(k)-1}, y_{n(k)-1}\right), G\left(y_{n(k)-1}, x_{n(k)-1}\right)\right)\right) \leq \varepsilon .
\end{array}\right.
$$

By definition of the metric $\Lambda$, we have

$$
d_{k}=d\left(G\left(x_{m(k)}, y_{m(k)}\right), G\left(x_{n(k)}, y_{n(k)}\right)\right)+d\left(G\left(y_{m(k)}, x_{m(k)}\right), G\left(y_{n(k)}, x_{n(k)}\right)\right)>\varepsilon
$$

and

$$
d\left(G\left(x_{m(k)}, y_{m(k)}\right), G\left(x_{n(k)-1}, y_{n(k)-1}\right)\right)+d\left(G\left(y_{m(k)}, x_{m(k)}\right), G\left(y_{n(k)-1}, x_{n(k)-1}\right)\right) \leq \varepsilon .
$$


Further from (3.12) and (3.13), for $k \geq 0$, we have

$$
\begin{aligned}
\varepsilon< & d_{k} \\
\leq & d\left(G\left(x_{m(k)}, y_{m(k)}\right), G\left(x_{n(k)-1}, y_{n(k)-1}\right)\right)+d\left(G\left(x_{n(k)-1}, y_{n(k)-1}\right), G\left(x_{n(k)}, y_{n(k)}\right)\right) \\
& +d\left(G\left(y_{m(k)}, x_{m(k)}\right), G\left(y_{n(k)-1}, x_{n(k)-1}\right)\right)+d\left(G\left(y_{n(k)-1}, x_{n(k)-1}\right), G\left(y_{n(k)}, x_{n(k)}\right)\right) \\
\leq & \varepsilon+\delta_{n(k)-1 .}
\end{aligned}
$$

Taking the limit as $k \rightarrow+\infty$ in the above inequality, we have, by (3.10),

$$
\lim _{k \rightarrow+\infty} d_{k}=\varepsilon^{+}
$$

Again, for all $k \geq 0$, we have

$$
\begin{aligned}
d_{k}= & d\left(G\left(x_{m(k)}, y_{m(k)}\right), G\left(x_{n(k)}, y_{n(k)}\right)\right)+d\left(G\left(y_{m(k)}, x_{m(k)}\right), G\left(y_{n(k)}, x_{n(k)}\right)\right) \\
\leq & d\left(G\left(x_{m(k)}, y_{m(k)}\right), G\left(x_{m(k)+1}, y_{m(k)+1}\right)\right)+d\left(G\left(x_{m(k)+1}, y_{m(k)+1}\right), G\left(x_{n(k)+1}, y_{n(k)+1}\right)\right) \\
& +d\left(G\left(x_{n(k)+1}, y_{n(k)+1}\right), G\left(x_{n(k)}, y_{n(k)}\right)\right)+d\left(G\left(y_{m(k)}, x_{m(k)}\right), G\left(y_{m(k)+1}, x_{m(k)+1}\right)\right) \\
& +d\left(G\left(y_{m(k)+1}, x_{m(k)+1}\right), G\left(y_{n(k)+1}, x_{n(k)+1}\right)\right)+d\left(G\left(y_{n(k)+1}, x_{n(k)+1}\right), G\left(y_{n(k)}, x_{n(k)}\right)\right) \\
= & d\left(G\left(x_{m(k)}, y_{m(k)}\right), G\left(x_{m(k)+1}, y_{m(k)+1}\right)\right)+d\left(G\left(y_{m(k)}, x_{m(k)}\right), G\left(y_{m(k)+1}, x_{m(k)+1}\right)\right) \\
& +d\left(G\left(x_{m(k)+1}, y_{m(k)+1}\right), G\left(x_{n(k)+1}, y_{n(k)+1}\right)\right)+d\left(G\left(y_{m(k)+1}, x_{m(k)+1}\right), G\left(y_{n(k)+1}, x_{n(k)+1}\right)\right) \\
& +d\left(G\left(x_{n(k)+1}, y_{n(k)+1}\right), G\left(x_{n(k)}, y_{n(k)}\right)\right)+d\left(G\left(y_{n(k)+1}, x_{n(k)+1}\right), G\left(y_{n(k)}, x_{n(k)}\right)\right) .
\end{aligned}
$$

Hence, for all $k \geq 0$,

$$
\begin{aligned}
d_{k} \leq & \delta_{m(k)}+\delta_{n(k)}+d\left(G\left(x_{m(k)+1}, y_{m(k)+1}\right), G\left(x_{n(k)+1}, y_{n(k)+1}\right)\right) \\
& +d\left(G\left(y_{m(k)+1}, x_{m(k)+1}\right), G\left(y_{n(k)+1}, x_{n(k)+1}\right)\right) .
\end{aligned}
$$

Using the property of $\phi$, we have

$$
\begin{aligned}
\phi\left(d_{k}\right)= & \phi\left(\delta_{m(k)}+\delta_{n(k)}+d\left(G\left(x_{m(k)+1}, y_{m(k)+1}\right), G\left(x_{n(k)+1}, y_{n(k)+1}\right)\right)\right. \\
& \left.+d\left(G\left(y_{m(k)+1}, x_{m(k)+1}\right), G\left(y_{n(k)+1}, x_{n(k)+1}\right)\right)\right) \\
\leq & \phi\left(\delta_{m(k)}+\delta_{n(k)}\right)+\phi\left(d\left(G\left(x_{m(k)+1}, y_{m(k)+1}\right), G\left(x_{n(k)+1}, y_{n(k)+1}\right)\right)\right) \\
& +\phi\left(d\left(G\left(y_{m(k)+1}, x_{m(k)+1}\right), G\left(y_{n(k)+1}, x_{n(k)+1}\right)\right)\right) .
\end{aligned}
$$

From (3.1), (3.4), and (3.12), for all $k \geq 0$, we have

$$
\begin{aligned}
\phi( & \left.d\left(G\left(x_{m(k)+1}, y_{m(k)+1}\right), G\left(x_{n(k)+1}, y_{n(k)+1}\right)\right)\right) \\
= & \phi\left(d\left(F\left(x_{m(k)}, y_{m(k)}\right), F\left(x_{n(k)}, y_{n(k)}\right)\right)\right) \\
\leq & \frac{1}{2} \phi\left(d\left(G\left(x_{m(k)}, y_{m(k)}\right), G\left(x_{n(k)}, y_{n(k)}\right)\right)+d\left(G\left(y_{m(k)}, x_{m(k)}\right), G\left(y_{n(k)}, x_{n(k)}\right)\right)\right) \\
& -\psi\left(\frac{d\left(G\left(x_{m(k)}, y_{m(k)}\right), G\left(x_{n(k)}, y_{n(k)}\right)\right)+d\left(G\left(y_{m(k)}, x_{m(k)}\right), G\left(y_{n(k)}, x_{n(k)}\right)\right)}{2}\right)
\end{aligned}
$$




$$
\begin{aligned}
& =\frac{1}{2} \phi\left(d_{k}\right)-\psi\left(\frac{d_{k}}{2}\right) \\
& \leq \frac{1}{2} \phi\left(d_{k}\right) .
\end{aligned}
$$

Also from (3.1), (3.4), and (3.12), for all $k \geq 0$, we have

$$
\begin{aligned}
\phi( & \left.d\left(G\left(y_{m(k)+1}, x_{m(k)+1}\right), G\left(y_{n(k)+1}, x_{n(k)+1}\right)\right)\right) \\
= & \phi\left(d\left(F\left(y_{m(k)}, x_{m(k)}\right), F\left(y_{n(k)}, x_{n(k)}\right)\right)\right) \\
\leq & \frac{1}{2} \phi\left(d\left(G\left(y_{m(k)}, x_{m(k)}\right), G\left(y_{n(k)}, x_{n(k)}\right)\right)+d\left(G\left(x_{m(k)}, y_{m(k)}\right), G\left(x_{n(k)}, y_{n(k)}\right)\right)\right) \\
& \quad-\psi\left(\frac{d\left(G\left(y_{m(k)}, x_{m(k)}\right), G\left(y_{n(k)}, x_{n(k)}\right)\right)+d\left(G\left(x_{m(k)}, y_{m(k)}\right), G\left(x_{n(k)}, y_{n(k)}\right)\right)}{2}\right) \\
= & \frac{1}{2} \phi\left(d_{k}\right)-\psi\left(\frac{d_{k}}{2}\right) \\
\leq & \frac{1}{2} \phi\left(d_{k}\right) .
\end{aligned}
$$

Inserting (3.16) and (3.17) in (3.15), we have

$$
\phi\left(d_{k}\right) \leq \phi\left(\delta_{m(k)}+\delta_{n(k)}\right)+\phi\left(d_{k}\right)-2 \psi\left(\frac{d_{k}}{2}\right)
$$

Letting $k \rightarrow+\infty$ in the above inequality, we obtain

$$
\phi(\varepsilon) \leq \phi(0)+\phi(\varepsilon)-2 \lim _{k \rightarrow+\infty} \psi\left(\frac{d_{k}}{2}\right)=\phi(\varepsilon)-2 \lim _{d_{k} \rightarrow \varepsilon^{+}} \psi\left(\frac{d_{k}}{2}\right)<\phi(\varepsilon),
$$

which is a contradiction. Hence $\left(G\left(x_{n}, y_{n}\right), G\left(y_{n}, x_{n}\right)\right)$ is a Cauchy sequence in $(X \times X, \Lambda)$, which implies that $\left(G\left(x_{n}, y_{n}\right)\right)$ and $\left(G\left(y_{n}, x_{n}\right)\right)$ are Cauchy sequences in $(X, d)$. Now, since $(X, d)$ is complete, there exist $x, y \in X$ such that

$$
\begin{aligned}
& \lim _{n \rightarrow+\infty} G\left(x_{n}, y_{n}\right)=\lim _{n \rightarrow+\infty} F\left(x_{n}, y_{n}\right)=x \quad \text { and } \\
& \lim _{n \rightarrow+\infty} G\left(y_{n}, x_{n}\right)=\lim _{n \rightarrow+\infty} F\left(y_{n}, x_{n}\right)=y .
\end{aligned}
$$

Since the pair $\{F, G\}$ satisfies the generalized compatibility, from (3.20), we get

$$
\lim _{n \rightarrow+\infty} d\left(F\left(G\left(x_{n}, y_{n}\right), G\left(y_{n}, x_{n}\right)\right), G\left(F\left(x_{n}, y_{n}\right), F\left(y_{n}, x_{n}\right)\right)\right)=0
$$

and

$$
\lim _{n \rightarrow+\infty} d\left(F\left(G\left(y_{n}, x_{n}\right), G\left(x_{n}, y_{n}\right)\right), G\left(F\left(y_{n}, x_{n}\right), F\left(x_{n}, y_{n}\right)\right)\right)=0
$$

Suppose that $F$ is continuous. For all $n \geq 0$, we have

$$
\begin{aligned}
& d\left(G(x, y), F\left(G\left(x_{n}, y_{n}\right), G\left(y_{n}, x_{n}\right)\right)\right) \\
& \quad \leq d\left(G(x, y), G\left(F\left(x_{n}, y_{n}\right), F\left(y_{n}, x_{n}\right)\right)\right) \\
& \quad+d\left(G\left(F\left(x_{n}, y_{n}\right), F\left(y_{n}, x_{n}\right)\right), F\left(G\left(x_{n}, y_{n}\right), G\left(y_{n}, x_{n}\right)\right)\right) .
\end{aligned}
$$


Taking the limit as $n \rightarrow+\infty$, using (3.20), (3.21), and the fact that $F$ and $G$ are continuous, we have

$$
G(x, y)=F(x, y) \text {. }
$$

Similarly, using (3.20), (3.21), and the fact that $F$ and $G$ are continuous, we have

$$
G(y, x)=F(y, x) .
$$

Thus $(x, y)$ is a coupled coincidence point of $F$ and G. Now, suppose that (b) holds. By (3.4) and (3.20), we have $\left(G\left(x_{n}, y_{n}\right)\right)$ is non-decreasing sequence, $G\left(x_{n}, y_{n}\right) \rightarrow x$ and $\left(G\left(y_{n}, x_{n}\right)\right)$ is non-decreasing sequence, $G\left(y_{n}, x_{n}\right) \rightarrow y$ as $n \rightarrow+\infty$. Thus for all $n \in \mathbb{N}$, we have

$$
G\left(x_{n}, y_{n}\right) \preceq x \quad \text { and } \quad G\left(y_{n}, x_{n}\right) \succeq y \text {. }
$$

Since the pair $\{F, G\}$ satisfies the generalized compatibility and $G$ is continuous, by (3.21) and (3.22), we have

$$
\begin{aligned}
\lim _{n \rightarrow+\infty} G\left(G\left(x_{n}, y_{n}\right), G\left(y_{n}, x_{n}\right)\right) & =G(x, y) \\
& =\lim _{n \rightarrow+\infty} G\left(F\left(x_{n}, y_{n}\right), F\left(y_{n}, x_{n}\right)\right) \\
& =\lim _{n \rightarrow+\infty} F\left(G\left(x_{n}, y_{n}\right), G\left(y_{n}, x_{n}\right)\right)
\end{aligned}
$$

and

$$
\begin{aligned}
\lim _{n \rightarrow+\infty} G\left(G\left(y_{n}, x_{n}\right), G\left(x_{n}, y_{n}\right)\right) & =G(y, x) \\
& =\lim _{n \rightarrow+\infty} G\left(F\left(y_{n}, x_{n}\right), F\left(x_{n}, y_{n}\right)\right) \\
& =\lim _{n \rightarrow+\infty} F\left(G\left(y_{n}, x_{n}\right), G\left(x_{n}, y_{n}\right)\right) .
\end{aligned}
$$

Now, we have

$$
\begin{aligned}
d(G(x, y), F(x, y)) & \leq \lim _{n \rightarrow+\infty} d\left(G\left(F\left(x_{n}, y_{n}\right), F\left(y_{n}, x_{n}\right)\right), F(x, y)\right) \\
& =\lim _{n \rightarrow+\infty} d\left(F\left(G\left(x_{n}, y_{n}\right), G\left(y_{n}, x_{n}\right)\right), F(x, y)\right) .
\end{aligned}
$$

Since $G$ has the mixed monotone property, it follows from (3.25) that $G\left(G\left(x_{n}, y_{n}\right)\right.$, $\left.G\left(y_{n}, x_{n}\right)\right) \preceq G(x, y)$ and $G\left(G\left(y_{n}, x_{n}\right), G\left(x_{n}, y_{n}\right)\right) \succeq G(y, x)$. Now using (3.1), (3.26), and (3.27), we get

$$
\begin{aligned}
\phi( & d(G(x, y), F(x, y))) \\
\leq & \lim _{n \rightarrow+\infty} \frac{1}{2} \phi\left(d\left(G\left(G\left(x_{n}, y_{n}\right), G\left(y_{n}, x_{n}\right)\right), G(x, y)\right)+d\left(G\left(G\left(y_{n}, x_{n}\right), G\left(x_{n}, y_{n}\right)\right), G(y, x)\right)\right) \\
& -\psi\left(\frac{d\left(G\left(G\left(x_{n}, y_{n}\right), G\left(y_{n}, x_{n}\right)\right), G(x, y)\right)+d\left(G\left(G\left(y_{n}, x_{n}\right), G\left(x_{n}, y_{n}\right)\right), G(y, x)\right)}{2}\right) .
\end{aligned}
$$

Then we obtain $G(x, y)=F(x, y)$. Similarly, we can show that $G(y, x)=F(y, x)$. 
The commuting maps $\{F, G\}$ are obviously generalized compatible, thus we obtain the following.

Corollary 16 Let $(X, \preceq)$ be a partially ordered set such that there exists a complete metric $d$ on $X$. Assume that $F, G: X \times X \rightarrow X$ are two commuting mappings such that $F$ is $G$-increasing with respect to $\preceq, G$ is continuous and has the mixed monotone property, and there exist two elements $x_{0}, y_{0} \in X$ with

$$
G\left(x_{0}, y_{0}\right) \preceq F\left(x_{0}, y_{0}\right) \quad \text { and } \quad G\left(y_{0}, x_{0}\right) \succeq F\left(y_{0}, x_{0}\right) .
$$

Suppose that the inequalities (3.1) and (3.2) hold and either

(a) $F$ is continuous or

(b) $X$ has the following properties:

(i) if a non-decreasing sequence $\left\{x_{n}\right\} \rightarrow x$, then $x_{n} \preceq x$ for all $n$,

(ii) if a non-increasing sequence $\left\{y_{n}\right\} \rightarrow y$, then $y \preceq y_{n}$ for all $n$.

Then $F$ and $G$ have a coupled coincidence point in $X$.

Definition 17 Let $(X, \preceq)$ be a partially ordered set, $F: X \times X \rightarrow X$ and $g: X \rightarrow X$. We say that $F$ is $g$-increasing with respect to $\preceq$ if for any $x, y \in X$,

$$
g x_{1} \preceq g x_{2} \quad \text { implies } \quad F\left(x_{1}, y\right) \preceq F\left(x_{2}, y\right)
$$

and

$$
g y_{1} \preceq g y_{2} \quad \text { implies } \quad F\left(x, y_{1}\right) \preceq F\left(x, y_{2}\right) .
$$

Now, we deduce an analogous result to Theorem 3.1 of Alotaibi and Alsulami [34] (Theorem 6) without $g$-mixed monotone property of $F$.

Corollary 18 Let $(X, \preceq)$ be a partially ordered set and suppose there is a metric d on $X$ such that $(X, d)$ is a complete metric space. Let $F: X \times X \rightarrow X$ and $g: X \rightarrow X$ be two mappings such that $F$ is g-increasing with respect to $\preceq$, and there exist $\phi \in \Phi$ and $\psi \in \Psi$ such that

$$
\begin{aligned}
\phi(d(F(x, y), F(u, v))) \leq & \frac{1}{2} \phi(d(g x, g u)+d(g y, g v)) \\
& -\psi\left(\frac{d(g x, g u)+d(g y, g v)}{2}\right)
\end{aligned}
$$

for all $x, y, u, v \in X$, with $g x \preceq g u$ and $g y \succeq g v$. Suppose that $F(X \times X) \subseteq g(X)$, $g$ is continuous and monotone increasing with respect to $\preceq$, and the pair $\{F, g\}$ is compatible. Also suppose that either

(a) $F$ is continuous or

(b) $X$ has the following properties:

(i) if a non-decreasing sequence $\left\{x_{n}\right\} \rightarrow x$, then $x_{n} \preceq x$ for all $n$,

(ii) if a non-increasing sequence $\left\{y_{n}\right\} \rightarrow y$, then $y \preceq y_{n}$ for all $n$.

If there exist two elements $x_{0}, y_{0} \in X$ with

$$
g x_{0} \preceq F\left(x_{0}, y_{0}\right) \text { and } g y_{0} \succeq F\left(y_{0}, x_{0}\right) .
$$

Then $F$ and $g$ have a coupled coincidence point. 
Corollary 19 Let $(X, \preceq)$ be a partially ordered set and suppose there is a metric $d$ on $X$ such that $(X, d)$ is a complete metric space. Let $F: X \times X \rightarrow X$ and $g: X \rightarrow X$ be two mappings such that $F$ is $g$-increasing with respect to $\preceq$, and there exist $\phi \in \Phi$ and $\psi \in \Psi$ such that

$$
\begin{aligned}
\phi(d(F(x, y), F(u, v))) \leq & \frac{1}{2} \phi(d(g x, g u)+d(g y, g v)) \\
& -\psi\left(\frac{d(g x, g u)+d(g y, g v)}{2}\right)
\end{aligned}
$$

for all $x, y, u, v \in X$, with $g x \preceq g u$ and $g y \succeq g v$. Suppose that $F(X \times X) \subseteq g(X), g$ is continuous and monotone increasing with respect to $\preceq$, and the pair $\{F, g\}$ is commuting. Also suppose that either

(a) $F$ is continuous or

(b) $X$ has the following properties:

(i) if a non-decreasing sequence $\left\{x_{n}\right\} \rightarrow x$, then $x_{n} \preceq x$ for all $n$,

(ii) if a non-increasing sequence $\left\{y_{n}\right\} \rightarrow y$, then $y \leq y_{n}$ for all $n$.

If there exist two elements $x_{0}, y_{0} \in X$ with

$$
g x_{0} \preceq F\left(x_{0}, y_{0}\right) \text { and } g y_{0} \succeq F\left(y_{0}, x_{0}\right) \text {. }
$$

Then F and $g$ have a coupled coincidence point.

Definition 20 Let $(X, \preceq)$ be a partially ordered set, $F: X \times X \rightarrow X$. We say that $F$ is increasing with respect to $\preceq$ if for any $x, y \in X$,

$$
x_{1} \preceq x_{2} \quad \text { implies } \quad F\left(x_{1}, y\right) \preceq F\left(x_{2}, y\right)
$$

and

$$
y_{1} \preceq y_{2} \quad \text { implies } \quad F\left(x, y_{1}\right) \preceq F\left(x, y_{2}\right) .
$$

The following result provides the conclusion of the main results of Luong and Thuan [35] without the mixed monotone property of the involved mapping $F$.

Corollary 21 [35] Let $(X, \preceq)$ be a partially ordered set and suppose there is a metric $d$ on $X$ such that $(X, d)$ is a complete metric space. Assume that $F: X \times X \rightarrow X$ is an increasing map with respect to $\preceq$ and there exist two elements $x_{0}, y_{0} \in X$ with

$$
x_{0} \preceq F\left(x_{0}, y_{0}\right) \quad \text { and } \quad y_{0} \succeq F\left(y_{0}, x_{0}\right) .
$$

Suppose there exist $\phi \in \Phi$ and $\psi \in \Psi$ such that

$$
\begin{aligned}
\phi(d(F(x, y), F(u, v))) \leq & \frac{1}{2} \phi(d(x, u)+d(y, v)) \\
& -\psi\left(\frac{d(x, u)+d(y, v)}{2}\right)
\end{aligned}
$$

for all $x, y, u, v \in X$, with $x \preceq u$ and $y \succeq v$. Also suppose that either 
(a) $F$ is continuous or

(b) $X$ has the following properties:

(i) if a non-decreasing sequence $\left\{x_{n}\right\} \rightarrow x$, then $x_{n} \preceq x$ for all $n$,

(ii) if a non-increasing sequence $\left\{y_{n}\right\} \rightarrow y$, then $y \preceq y_{n}$ for all $n$.

Then $F$ has a coupled fixed point.

Corollary 22 Let $(X, \preceq)$ be a partially ordered set and suppose there is a metric $d$ on $X$ such that $(X, d)$ is a complete metric space. Assume that $F: X \times X \rightarrow X$ be an increasing map with respect to $\preceq$ and there exist two elements $x_{0}, y_{0} \in X$ with

$$
x_{0} \preceq F\left(x_{0}, y_{0}\right) \text { and } y_{0} \succeq F\left(y_{0}, x_{0}\right) .
$$

Suppose there exists $\psi \in \Psi$ such that

$$
\begin{aligned}
d(F(x, y), F(u, v)) \leq & \frac{d(x, u)+d(y, v)}{2} \\
& -\psi\left(\frac{d(x, u)+d(y, v)}{2}\right)
\end{aligned}
$$

for all $x, y, u, v \in X$, with $x \preceq u$ and $y \succeq v$. Also suppose that either

(a) $F$ is continuous or

(b) $X$ has the following properties:

(i) if a non-decreasing sequence $\left\{x_{n}\right\} \rightarrow x$, then $x_{n} \preceq x$ for all $n$,

(ii) if a non-increasing sequence $\left\{y_{n}\right\} \rightarrow y$, then $y \preceq y_{n}$ for all $n$.

Then $F$ has a coupled fixed point.

The conclusion of the main results of Bhaskar and Lakshmikantham [21] without the mixed monotone property of the involved mapping $F$ is obtained in the following corollary.

Corollary 23 Let $(X, \preceq)$ be a partially ordered set and suppose there is a metric $d$ on $X$ such that $(X, d)$ is a complete metric space. Assume that $F: X \times X \rightarrow X$ be an increasing map with respect to $\preceq$ and there exist two elements $x_{0}, y_{0} \in X$ with

$$
x_{0} \preceq F\left(x_{0}, y_{0}\right) \text { and } y_{0} \succeq F\left(y_{0}, x_{0}\right) .
$$

Suppose there exists a real number $k \in[0,1)$ such that

$$
d(F(x, y), F(u, v)) \leq \frac{k}{2}(d(x, u)+d(y, v))
$$

for all $x, y, u, v \in X$, with $x \preceq u$ and $y \succeq v$. Also suppose that either

(a) $F$ is continuous or

(b) $X$ has the following properties:

(i) if a non-decreasing sequence $\left\{x_{n}\right\} \rightarrow x$, then $x_{n} \preceq x$ for all $n$,

(ii) if a non-increasing sequence $\left\{y_{n}\right\} \rightarrow y$, then $y \preceq y_{n}$ for all $n$.

Then $F$ has a coupled fixed point. 
Now we prove the uniqueness of the coupled coincidence point. Note that if $(X, \preceq)$ is a partially ordered set, then we endow the product $X \times X$ with the following partial order relation, for all $(x, y),(u, v) \in X \times X$ :

$$
(x, y) \preceq(u, v) \quad \text { if and only if } \quad G(x, y) \preceq G(u, v) \quad \text { and } \quad G(y, x) \succeq G(v, u) \text {, }
$$

where $G: X \times X \rightarrow X \times X$ is one-one.

Theorem 24 In addition to the hypotheses of Theorem 15, suppose that for every $(x, y)$, $(z, t)$ in $X \times X$, there exists another $(u, v)$ in $X \times X$ which is comparable to $(x, y)$ and $(z, t)$, then $F$ and $G$ have a unique coupled coincidence point.

Proof From Theorem 15, the set of coupled coincidence points of $F$ and $G$ is nonempty. Suppose $(x, y)$ and $(z, t)$ are coupled coincidence points of $F$ and $G$, that is,

$$
\left\{\begin{array}{l}
F(x, y)=G(x, y) \\
F(y, x)=G(y, x)
\end{array}\right.
$$

and

$$
\left\{\begin{array}{l}
F(z, t)=G(z, t) \\
F(t, z)=G(t, z)
\end{array}\right.
$$

Now we prove that $G(x, y)=G(z, t)$ and $G(y, x)=G(t, z)$. By assumption, there exists $(u, v)$ in $X \times X$ that is comparable to $(x, y)$ and $(z, t)$. We define sequences $\left\{G\left(u_{n}, v_{n}\right)\right\}$ and $\left\{G\left(v_{n}, u_{n}\right)\right\}$ as follows, with $u_{0}=u, v_{0}=v$ :

$$
F\left(u_{n}, v_{n}\right)=G\left(u_{n+1}, v_{n+1}\right), \quad F\left(v_{n}, u_{n}\right)=G\left(v_{n+1}, u_{n+1}\right) \quad \text { for all } n \in \mathbb{N} .
$$

Since $(u, v)$ is comparable to $(x, y)$, we assume that $(x, y) \preceq(u, v)=\left(u_{0}, v_{0}\right)$. Which implies $G(x, y) \preceq G\left(u_{0}, v_{0}\right)$ and $G(y, x) \succeq G\left(v_{0}, u_{0}\right)$. We suppose that $(x, y) \preceq\left(u_{n}, v_{n}\right)$ for some $n$. We prove that

$$
(x, y) \preceq\left(u_{n+1}, v_{n+1}\right) .
$$

Since $F$ is $G$ increasing, we have $G(x, y) \preceq G\left(u_{n}, v_{n}\right)$ implies $F(x, y) \preceq F\left(u_{n}, v_{n}\right)$ and $G(y, x) \succeq$ $G\left(v_{n}, u_{n}\right)$ implies $F(y, x) \succeq F\left(v_{n}, u_{n}\right)$. Now

$$
G(x, y)=F(x, y) \preceq F\left(u_{n}, v_{n}\right)=G\left(u_{n+1}, v_{n+1}\right)
$$

and

$$
G(y, x)=F(y, x) \succeq F\left(v_{n}, u_{n}\right)=G\left(v_{n+1}, u_{n+1}\right) .
$$

Thus we have

$$
(x, y) \preceq\left(u_{n}, v_{n}\right) \quad \text { for all } n \text {. }
$$


Using (3.1) and (3.28), we have

$$
\begin{aligned}
\phi( & \left.d\left(G(x, y), G\left(u_{n+1}, v_{n+1}\right)\right)\right) \\
= & \phi\left(d\left(F(x, y), F\left(u_{n}, v_{n}\right)\right)\right) \\
\leq & \frac{1}{2} \phi\left(d\left(G(x, y), G\left(u_{n}, v_{n}\right)\right)+d\left(G(y, x), G\left(v_{n}, u_{n}\right)\right)\right) \\
& -\psi\left(\frac{d\left(G(x, y), G\left(u_{n}, v_{n}\right)\right)+d\left(G(y, x), G\left(v_{n}, u_{n}\right)\right)}{2}\right) .
\end{aligned}
$$

Similarly

$$
\begin{aligned}
\phi( & \left.d\left(G\left(v_{n+1}, u_{n+1}\right), G(y, x)\right)\right) \\
= & \phi\left(d\left(F\left(v_{n}, u_{n}\right), F(y, x)\right)\right) \\
\leq & \frac{1}{2} \phi\left(d\left(G\left(v_{n}, u_{n}\right), G(y, x)\right)+d\left(G\left(u_{n}, v_{n}\right), G(x, y)\right)\right) \\
& -\psi\left(\frac{d\left(G\left(v_{n}, u_{n}\right), G(y, x)\right)+d\left(G\left(u_{n}, v_{n}\right), G(x, y)\right)}{2}\right) .
\end{aligned}
$$

Using (3.29), (3.30), and the property of $\phi$, we have

$$
\begin{gathered}
\phi\left(d\left(G(x, y), G\left(u_{n+1}, v_{n+1}\right)\right)+d\left(G(y, x), G\left(v_{n+1}, u_{n+1}\right)\right)\right) \\
\leq \phi\left(d\left(F(x, y), F\left(u_{n}, v_{n}\right)\right)\right)+\phi\left(d\left(G\left(v_{n+1}, u_{n+1}\right), G(y, x)\right)\right) \\
\leq \phi\left(d\left(G(x, y), G\left(u_{n}, v_{n}\right)\right)+d\left(G(y, x), G\left(v_{n}, u_{n}\right)\right)\right) \\
\quad-2 \psi\left(\frac{d\left(G(x, y), G\left(u_{n}, v_{n}\right)\right)+d\left(G(y, x), G\left(v_{n}, u_{n}\right)\right)}{2}\right),
\end{gathered}
$$

which implies that

$$
\begin{gathered}
\phi\left(d\left(G(x, y), G\left(u_{n+1}, v_{n+1}\right)\right)+d\left(G(y, x), G\left(v_{n+1}, u_{n+1}\right)\right)\right) \\
\leq \phi\left(d\left(G(x, y), G\left(u_{n}, v_{n}\right)\right)+d\left(G(y, x), G\left(v_{n}, u_{n}\right)\right)\right) .
\end{gathered}
$$

By using the property of $\phi$, we get

$$
\begin{gathered}
d\left(G(x, y), G\left(u_{n+1}, v_{n+1}\right)\right)+d\left(G(y, x), G\left(v_{n+1}, u_{n+1}\right)\right) \\
\leq d\left(G(x, y), G\left(u_{n}, v_{n}\right)\right)+d\left(G(y, x), G\left(v_{n}, u_{n}\right)\right) .
\end{gathered}
$$

This implies that the sequence $\left\{d\left(G(x, y), G\left(u_{n}, v_{n}\right)\right)+d\left(G(y, x), G\left(v_{n}, u_{n}\right)\right)\right\}$ is decreasing. Therefore, there exists $l \geq 0$ such that

$$
\lim _{n \rightarrow+\infty}\left[d\left(G(x, y), G\left(u_{n}, v_{n}\right)\right)+d\left(G(y, x), G\left(v_{n}, u_{n}\right)\right)\right]=l
$$

Now we show that $l=0$. We suppose on the contrary that $l>0$. Taking the limit as $n \rightarrow \infty$ in (3.31) and using the property of $\psi$, we have

$$
\phi(l) \leq \phi(l)-2 \lim _{n \rightarrow+\infty} \psi\left(\frac{d\left(G(x, y), G\left(u_{n}, v_{n}\right)\right)+d\left(G(y, x), G\left(v_{n}, u_{n}\right)\right)}{2}\right)<\phi(l),
$$


a contradiction. Thus $l=0$, that is,

$$
\lim _{n \rightarrow+\infty}\left[d\left(G(x, y), G\left(u_{n}, v_{n}\right)\right)+d\left(G(y, x), G\left(v_{n}, u_{n}\right)\right)\right]=0 .
$$

This implies that

$$
\lim _{n \rightarrow+\infty} d\left(G(x, y), G\left(u_{n}, v_{n}\right)\right)=\lim _{n \rightarrow+\infty} d\left(G(y, x), G\left(v_{n}, u_{n}\right)\right)=0
$$

Similarly, we show that

$$
\lim _{n \rightarrow+\infty} d\left(G(z, t), G\left(u_{n}, v_{n}\right)\right)=\lim _{n \rightarrow+\infty} d\left(G(t, z), G\left(v_{n}, u_{n}\right)\right)=0 .
$$

Using (3.33) and (3.34), we have $G(x, y)=G(z, t)$ and $G(y, x)=G(t, z)$.

Example 25 Let $X=[0,1]$ endowed with the natural ordering of real numbers. We endow $X$ with the standard metric $X$

$$
d(x, y)=|x-y|
$$

for all $x, y \in X$. Then $(X, d)$ is a complete metric space. Define the mappings $F, G: X \times X \rightarrow$ $X$ as follows:

$$
F(x, y)= \begin{cases}\frac{x^{2}-y^{2}}{3} & \text { if } x \geq y, \\ 0 & \text { if } x<y\end{cases}
$$

and

$$
G(x, y)= \begin{cases}x^{2}-y^{2} & \text { if } x \geq y \\ 0 & \text { if } x<y .\end{cases}
$$

First we prove that $F$ is $G$-increasing.

Let $(x, y),(u, v) \in X \times X$ with $G(x, y) \leq G(u, v)$. We consider the following cases.

Case 1: If $x<y$, then $F(x, y)=0 \leq F(u, v)$.

Case 2: If $x \geq y$, and if $u \geq v$, then

$$
\begin{aligned}
G(x, y) \leq G(u, v) & \Rightarrow x^{2}-y^{2} \leq u^{2}-v^{2} \Rightarrow \frac{x^{2}-y^{2}}{3} \leq \frac{u^{2}-v^{2}}{3} \\
& \Rightarrow F(x, y) \leq F(u, v) .
\end{aligned}
$$

But if $u<v$, then

$$
G(x, y) \leq G(u, v) \Rightarrow 0 \leq x^{2}-y^{2} \leq 0 \quad \Rightarrow \quad x^{2}=y^{2} \quad \Rightarrow \quad F(x, y)=0 \leq F(u, v) .
$$

Thus we see that $F$ is $G$-increasing.

Now we prove that for any $x, y \in X$, there exist $u, v \in X$ such that

$$
\left\{\begin{array}{l}
F(x, y)=G(u, v), \\
F(y, x)=G(v, u) .
\end{array}\right.
$$

Let $(x, y) \in X \times X$ be fixed. We consider the following cases. 
Case 1: If $x=y$, then we have $F(x, y)=0=G(x, y)$ and $F(y, x)=0=G(y, x)$.

Case 2: If $x>y$, then we have $F(x, y)=\frac{x^{2}-y^{2}}{3}=G\left(\frac{x}{3}, \frac{y}{3}\right)$ and $F(y, x)=0=G\left(\frac{y}{3}, \frac{x}{3}\right)$.

Case 3: If $x<y$, then we have $F(x, y)=0=G\left(\frac{x}{3}, \frac{y}{3}\right)$ and $F(y, x)=\frac{y^{2}-x^{2}}{3}=G\left(\frac{y}{3}, \frac{x}{3}\right)$.

Now we prove that $G$ is continuous and has the mixed monotone property.

Clearly $G$ is continuous. Let $(x, y) \in X \times X$ be fixed. Suppose that $x_{1}, x_{2} \in X$ are such that $x_{1}<x_{2}$. We discuss the following cases.

Case 1: If $x_{1}<y$, then we have $G\left(x_{1}, y\right)=0 \leq G\left(x_{2}, y\right)$.

Case 2: If $x_{2}>x_{1}>y$, then we have $G\left(x_{1}, y\right)=x_{1}^{2}-y^{2} \leq x_{2}^{2}-y^{2}=G\left(x_{2}, y\right)$.

Similarly, we can show that if $y_{1}, y_{2} \in X$ are such that $y_{1}<y_{2}$, then $G\left(x, y_{1}\right) \geq G\left(x, y_{2}\right)$.

Now, we prove that the pair $\{F, G\}$ satisfies the generalized compatibility hypothesis.

Let $\left(x_{n}\right)$ and $\left(y_{n}\right)$ be two sequences in $X$ such that

$$
t_{1}=\lim _{n \rightarrow+\infty} F\left(x_{n}, y_{n}\right)=\lim _{n \rightarrow+\infty} G\left(x_{n}, y_{n}\right)
$$

and

$$
t_{2}=\lim _{n \rightarrow+\infty} F\left(y_{n}, x_{n}\right)=\lim _{n \rightarrow+\infty} G\left(y_{n}, x_{n}\right) .
$$

Then we must have $t_{1}=t_{2}=0$ and one can easily prove that

$$
\left\{\begin{array}{l}
\lim _{n \rightarrow+\infty} d\left(F\left(G\left(x_{n}, y_{n}\right), G\left(y_{n}, x_{n}\right)\right), G\left(F\left(x_{n}, y_{n}\right), F\left(y_{n}, x_{n}\right)\right)\right)=0 \\
\lim _{n \rightarrow+\infty} d\left(F\left(G\left(y_{n}, x_{n}\right), G\left(x_{n}, y_{n}\right)\right), G\left(F\left(y_{n}, x_{n}\right), F\left(x_{n}, y_{n}\right)\right)\right)=0 .
\end{array}\right.
$$

Now we prove that there exist two elements $x_{0}, y_{0} \in X$ with

$$
G\left(x_{0}, y_{0}\right) \preceq F\left(x_{0}, y_{0}\right) \quad \text { and } \quad G\left(y_{0}, x_{0}\right) \succeq F\left(y_{0}, x_{0}\right) \text {. }
$$

Since we have $G\left(0, \frac{1}{2}\right)=0=F\left(0, \frac{1}{2}\right)$ and $G\left(\frac{1}{2}, 0\right)=\frac{1}{4} \geq \frac{1}{12}=F\left(\frac{1}{2}, 0\right)$. Now, let $\phi:[0, \infty) \rightarrow$ $[0, \infty)$ be defined as $\phi(t)=\frac{3}{4} t$, for all $t \in[0, \infty)$ and let $\psi:[0, \infty) \rightarrow[0, \infty)$ be defined as $\psi(t)=\frac{3}{4} t$, for all $t \in[0, \infty)$. Clearly $\phi \in \Phi$ and $\psi \in \Psi$. We next verify the contraction (3.1) for all $x, y, u, v \in X$, with $G(x, y) \preceq G(u, v)$ and $G(v, u) \preceq G(y, x)$. We have

$$
\begin{aligned}
\phi(d(F(x, y), F(u, v)))= & \frac{3}{4}[d(F(x, y), F(u, v))] \\
& =\frac{3}{4}|F(x, y)-F(u, v)| \\
& =\frac{1}{4}|G(x, y)-G(u, v)| \\
& =\frac{1}{2} \frac{|G(x, y)-G(u, v)|}{2} \\
& \leq \frac{1}{2} \frac{|G(x, y)-G(u, v)|+|G(y, x)-G(v, u)|}{2} \\
= & \frac{3}{4} \frac{|G(x, y)-G(u, v)|+|G(y, x)-G(v, u)|}{2} \\
& -\frac{1}{4} \frac{|G(x, y)-G(u, v)|+|G(y, x)-G(v, u)|}{2} \\
= & \frac{3}{8}|G(x, y)-G(u, v)|+|G(y, x)-G(v, u)|
\end{aligned}
$$




$$
\begin{aligned}
& -\frac{1}{4} \frac{|G(x, y)-G(u, v)|+|G(y, x)-G(v, u)|}{2} \\
= & \frac{1}{2} \phi(d(G(x, y), G(u, v))+d(G(y, x), G(v, u))) \\
& -\psi\left(\frac{d(G(x, y), G(u, v))+d(G(y, x), G(v, u))}{2}\right) .
\end{aligned}
$$

Hence condition (3.1) is satisfied. Thus all the requirements of Theorem 15 are satisfied and $(0,0)$ is a coupled coincidence point of $F$ and $G$.

\section{Applications to the integral equations}

Fixed point theorems for monotone operators in ordered metric spaces are widely investigated and have found various applications in differential and integral equations (see [1, $9,10,14]$ and references therein). Motivated by the work in [2,35-38], we study the existence of solutions for a system of nonlinear integral equations using the results proved in the previous section.

Let $\Theta$ denote the class of those functions $\theta:[0, \infty) \rightarrow[0, \infty)$ which satisfies the following conditions:

(i) $\theta$ is increasing.

(ii) There exists $\psi \in \Psi$ such that $\theta(t)=\frac{t}{2}-\psi\left(\frac{t}{2}\right)$ for all $t \in[0, \infty)$.

Consider the integral equation

$$
x(t)=\int_{a}^{b}\left(K_{1}(t, s)+K_{2}(t, s)\right)(f(s, x(s))+g(s, x(s))) d s+h(t)
$$

for all $t \in[a, b]$. We assume that $K_{1}, K_{2}, f$, and $g$ satisfy the following conditions:

(i) $0 \leq K_{1}(t, s), 0 \leq K_{2}(t, s)$ for all $t, s \in[a, b]$.

(ii) There exist $\lambda, \mu>0$ and $\theta \in \Theta$ such that for all $x, y \in \mathbb{R}, x \geq y$,

$$
0 \leq f(t, x)-f(t, y) \leq \lambda \theta(x-y) \quad \text { and } \quad 0 \leq g(t, x)-g(t, y) \leq \mu \theta(x-y) \text {. }
$$

(iii) We have

$$
\max \{\lambda, \mu\} \sup _{t \in[a, b]} \int_{a}^{b}\left(K_{1}(t, s)+K_{2}(t, s)\right) d s \leq \frac{1}{2} .
$$

(iv) There exist continuous functions $z, w:[a, b] \rightarrow \mathbb{R}$ such that

$$
\begin{aligned}
z(t) \leq & \int_{a}^{b} K_{1}(t, s)(f(s, z(s))+g(s, w(s))) d s \\
& +\int_{a}^{b} K_{2}(t, s)(f(s, w(s))+g(s, z(s))) d s+h(t)
\end{aligned}
$$

and

$$
\begin{aligned}
w(t) \geq & \int_{a}^{b} K_{1}(t, s)(f(s, w(s))+g(s, z(s))) d s \\
& +\int_{a}^{b} K_{2}(t, s)(f(s, z(s))+g(s, w(s))) d s+h(t)
\end{aligned}
$$

for all $t \in[a, b]$. 
Theorem 26 Consider the integral equation (4.1) with $K_{1}, K_{2} \in C([a, b] \times[a, b], \mathbb{R}), f, g \in$ $C([a, b] \times \mathbb{R}, \mathbb{R})$ and $h \in C([a, b], \mathbb{R})$ and suppose that the conditions (i)-(iv) are satisfied. Then the integral equation (4.1) has a solution in $C([a, b], \mathbb{R})$.

Proof Let $X=C([a, b], \mathbb{R})$ denote the space of continuous functions defined on the interval $[a, b]$. We endowed $X$ with the metric $d: X \times X \rightarrow \mathbb{R}$ defined by

$$
d(x, y)=\sup _{t \in[a, b]}|x(t)-y(t)| \quad \text { for all } x, y \in X .
$$

It is clear that $(X, d)$ is a complete metric space and $(X, d, \preceq)$ is a complete ordered metric space if $x \preceq y$ whenever $x(t) \leq y(t)$ for all $t \in[a, b]$. Suppose $\left\{u_{n}\right\}$ is a monotone nondecreasing in $X$ that converges to $u \in X$. Then for every $t \in[a, b]$ the sequence of real numbers

$$
u_{1}(t) \leq u_{2}(t) \leq \cdots \leq u_{n}(t) \leq \cdots
$$

converges to $u(t)$. Therefore for all $t \in[a, b], n \in \mathbb{N}, u_{n}(t) \leq u(t)$. Hence $u_{n} \preceq u$ for all $n$. Similarly, we can verify that $\lim _{n} v(t)$ of a monotone non-increasing sequence $v_{n}(t)$ in $X$ is a lower bound for all the elements in the sequence. That is, $v \preceq v_{n}$ for all $n$. Therefore, condition (b) of Corollary 22 holds. Also, $X \times X=C([a, b], \mathbb{R}) \times C([a, b], \mathbb{R})$ is a partially ordered set if we define the following order relation on $X \times X$, for all $x, y, u, v \in X$, with $x \preceq u$ and $y \succeq v$.

Define the mapping $F: X \times X \rightarrow X$ by

$$
\begin{aligned}
F(x, y)(t)= & \int_{a}^{b} K_{1}(t, s)(f(s, x(s))+g(s, y(s))) d s \\
& +\int_{a}^{b} K_{2}(t, s)(f(s, y(s))+g(s, x(s))) d s+h(t)
\end{aligned}
$$

for all $t \in[a, b]$. Now we shall show that $F$ is increasing. For $x_{1} \preceq x_{2}$, that is, $x_{1}(t) \leq x_{2}(t)$ for all $t \in[a, b]$, we have

$$
\begin{aligned}
F\left(x_{1}, y\right)(t)-F\left(x_{2}, y\right)(t)= & \int_{a}^{b} K_{1}(t, s)\left(f\left(s, x_{1}(s)\right)+g(s, y(s))\right) d s \\
& +\int_{a}^{b} K_{2}(t, s)\left(f(s, y(s))+g\left(s, x_{1}(s)\right)\right) d s+h(t) \\
& -\int_{a}^{b} K_{1}(t, s)\left(f\left(s, x_{2}(s)\right)+g(s, y(s))\right) d s \\
& -\int_{a}^{b} K_{2}(t, s)\left(f(s, y(s))+g\left(s, x_{2}(s)\right)\right) d s-h(t) \\
= & \int_{a}^{b} K_{1}(t, s)\left(f\left(s, x_{1}(s)\right)-f\left(s, x_{2}(s)\right)\right) d s \\
& +\int_{a}^{b} K_{2}(t, s)\left(g\left(s, x_{1}(s)\right)-g\left(s, x_{2}(s)\right)\right) d s \\
\leq & 0 .
\end{aligned}
$$


Hence $F\left(x_{1}, y\right)(t) \leq F\left(x_{2}, y\right)(t)$ for all $t \in[a, b]$, that is, $F\left(x_{1}, y\right) \preceq F\left(x_{2}, y\right)$. Similarly, if $y_{1} \preceq y_{2}$, that is $y_{1}(t) \leq y_{2}(t)$ for all $t \in[a, b]$, we have

$$
\begin{aligned}
F\left(x, y_{1}\right)(t)-F\left(x, y_{2}\right)(t)= & \int_{a}^{b} K_{1}(t, s)\left(f(s, x(s))+g\left(s, y_{1}(s)\right)\right) d s \\
& +\int_{a}^{b} K_{2}(t, s)\left(f\left(s, y_{1}(s)\right)+g(s, x(s))\right) d s+h(t) \\
& -\int_{a}^{b} K_{1}(t, s)\left(f(s, x(s))+g\left(s, y_{2}(s)\right)\right) d s \\
& -\int_{a}^{b} K_{2}(t, s)\left(f\left(s, y_{2}(s)\right)+g(s, x(s))\right) d s-h(t) \\
= & \int_{a}^{b} K_{1}(t, s)\left(g\left(s, y_{1}(s)\right)-g\left(s, y_{2}(s)\right)\right) d s \\
& +\int_{a}^{b} K_{2}(t, s)\left(f\left(s, y_{1}(s)\right)-f\left(s, y_{2}(s)\right)\right) d s \\
\leq & 0 .
\end{aligned}
$$

Hence $F\left(x, y_{1}\right)(t) \leq F\left(x, y_{2}\right)(t)$ for all $t \in[a, b]$, that is, $F\left(x, y_{1}\right) \preceq F\left(x, y_{2}\right)$. Thus $F(x, y)$ is increasing. Now, for $x, y, u, v \in X$ such that $x \preceq u$ and $v \preceq y$, we have

$$
\begin{aligned}
d(F(x, y)(t)-F(u, v)(t)) & \\
= & \sup _{t \in[a, b]}|F(x, y)(t)-F(u, v)(t)| \\
= & \sup _{t \in[a, b]} \mid \int_{a}^{b} K_{1}(t, s)(f(s, x(s))+g(s, y(s))) d s \\
& +\int_{a}^{b} K_{2}(t, s)(f(s, y(s))+g(s, x(s))) d s+h(t) \\
& -\left(\int_{a}^{b} K_{1}(t, s)(f(s, u(s))+g(s, v(s))) d s\right. \\
& \left.+\int_{a}^{b} K_{2}(t, s)(f(s, v(s))+g(s, u(s))) d s+h(t)\right) \mid \\
= & \sup _{t \in[a, b]} \mid \int_{a}^{b} K_{1}(t, s)[(f(s, x(s))-f(s, u(s)))+(g(s, y(s))-g(s, v(s)))] d s \\
& +\int_{a}^{b} K_{2}(t, s)[(f(s, y(s))-f(s, v(s)))+(g(s, x(s))-g(s, u(s)))] d s \mid \\
\leq & \sup _{t \in[a, b]} \mid \int_{a}^{b} K_{1}(t, s)[\lambda \theta(x(s)-u(s))+\mu \theta(y(s)-v(s))] d s \\
& +\int_{a}^{b} K_{2}(t, s)[\lambda \theta(y(s)-v(s))+\mu \theta(x(s)-u(s))] d s \mid \\
\leq & \max \{\lambda, \mu\} \sup _{t \in[a, b]} \int_{a}^{b}\left(K_{1}(t, s)+K_{2}(t, s)\right) \\
& \times[\theta(x(s)-u(s))+\theta(y(s)-v(s))] d s .
\end{aligned}
$$


As the function $\theta$ is increasing and $u(t) \geq x(t)$ and $y(t) \geq v(t)$ for all $t \in[a, b]$, then $\theta(x(s)-$ $u(s)) \leq \theta(d(x, u)), \theta(y(s)-v(s)) \leq \theta(d(y, v))$, for all $s \in[a, b]$, we obtain

$$
\begin{aligned}
d(F(x, y), F(u, v)) & \leq \max \{\lambda, \mu\} \cdot[\theta(d(x, u))+\theta(d(y, v))] \cdot \sup _{t \in[a, b]} \int_{a}^{b}\left(K_{1}(t, s)+K_{2}(t, s)\right) \\
& \leq \frac{1}{2}[\theta(d(x, u))+\theta(d(y, v))] \\
& \leq \theta(d(x, u)+d(y, v)) \\
& \leq \frac{d(x, u)+d(y, v)}{2}-\psi\left(\frac{d(x, u)+d(y, v)}{2}\right) .
\end{aligned}
$$

Therefore, for $x \preceq u$ and $v \preceq y$, we have

$$
d(F(x, y), F(u, v)) \leq \frac{d(x, u)+d(y, v)}{2}-\psi\left(\frac{d(x, u)+d(y, v)}{2}\right)
$$

Also from condition (iv) we have $z(t) \leq F(z, w)(t)$ and $F(w, z)(t) \leq w(t)$ for all $t \in[a, b]$, that is, $z \preceq F(z, w)$ and $F(w, z) \preceq w$. Thus all of the hypotheses of Corollary 22 are satisfied and the mapping $F$ has a coupled fixed point that is a solution in $X=C([a, b], \mathbb{R})$ of the integral equation (4.1).

\section{Competing interests}

The authors declare that they have no competing interests.

\section{Authors' contributions}

All authors contributed equally and significantly in writing this article. All authors read and approved the final manuscript.

\section{Author details}

${ }^{1}$ Department of Mathematics, King Abdulaziz University, P.O. Box 80203, Jeddah, 21589, Saudi Arabia. ${ }^{2}$ Department of Mathematics and Applied Mathematics, University of Pretoria, Lynwood Road, Pretoria, 002, South Africa. ${ }^{3}$ Department of Mathematics, COMSATS Institute of Information Technology, Chack Shahzad, Islamabad, 44000, Pakistan.

\section{Acknowledgements}

This article was funded by the Deanship of Scientific Research (DSR), King Abdulaziz University, Jeddah. Therefore, the first author acknowledges with thanks DSR, KAU for financial support.

Received: 30 September 2013 Accepted: 27 February 2014 Published: 13 Mar 2014

\section{References}

1. Ran, ACM, Reurings, MCB: A fixed point theorem in partially ordered sets and some applications to matrix equations. Proc. Am. Math. Soc. 132, 1435-1443 (2004)

2. Agarwal, RP, Hussain, N, Taoudi, MA: Fixed point theorems in ordered Banach spaces and applications to nonlinear integral equations. Abstr. Appl. Anal. 2012, Article ID 245872 (2012)

3. Amini-Harandi, A, Emami, H: A fixed point theorem for contraction type maps in partially ordered metric spaces and application to ordinary differential equations. Nonlinear Anal. 72, 2238-2242 (2010)

4. Arshad, M, Karapınar, E, Ahmad, J: Some unique fixed point theorem for rational contractions in partially ordered metric spaces. J. Inequal. Appl. 2013, 248 (2013)

5. Ćirić, LB, Cakić, N, Rajović, M, Ume, JS: Monotone generalized nonlinear contractions in partially ordered metric spaces. Fixed Point Theory Appl. 2008, Article ID 131294 (2008)

6. Harjani, J, Sadarangani, K: Generalized contractions in partially ordered metric spaces and applications to ordinary differential equations. Nonlinear Anal. 72,1188-1197 (2010)

7. Kutbi, MA, Ahmad, J, Hussain, N, Arshad, M: Common fixed point results for mappings with rational expressions. Abstr. Appl. Anal. 2013, Article ID 549518 (2013)

8. Nashine, HK, Altun, l: Fixed point theorems for generalized weakly contractive condition in ordered metric spaces. Fixed Point Theory Appl. 2011, Article ID 132367 (2011)

9. Nieto, JJ, Rodríguez-López, R: Contractive mapping theorems in partially ordered sets and applications to ordinary differential equations. Order 22, 223-239 (2005)

10. Nieto, JJ, Rodríguez-López, R: Existence and uniqueness of fixed point in partially ordered sets and applications to ordinary differential equations. Acta Math. Sin. Engl. Ser. 23, 2205-2212 (2007) 
11. O'Regan, D, Petruşel, A: Fixed point theorems for generalized contractions in ordered metric spaces. J. Math. Anal. Appl. 341, 1241-1252 (2008)

12. Takahashi, W: Nonlinear Functional Analysis - Fixed Point Theory and Its Applications. Yokohama Publishers, Yokohama (2000)

13. Takahashi, W, Lin, L-J, Wang, SY: Fixed point theorems for contractively generalized hybrid mappings in complete metric spaces. J. Nonlinear Convex Anal. 13(2), 195-206 (2012)

14. Wu, Y: New fixed point theorems and applications of mixed monotone operator. J. Math. Anal. Appl. 341, 883-893 (2008)

15. Mustafa, Z, Roshan, JR, Parvaneh, V: Coupled coincidence point results for $(\psi, \varphi)$-weakly contractive mappings in partially ordered $G_{b}$-metric spaces. Fixed Point Theory Appl. 2013, 206 (2013)

16. Roshan, JR, Parvaneh, V, Altun, I: Some coincidence point results in ordered b-metric spaces and applications in a system of integral equations. Appl. Math. Comput. 226, 725-737 (2014)

17. Guo, D, Lakshmikantham, V: Coupled fixed points of nonlinear operators with applications. Nonlinear Anal. 11, 623-632 (1987)

18. Alsulami, SM, Hussain, N, Alotaibi, A: Coupled fixed and coincidence points for monotone operators in partial metric spaces. Fixed Point Theory Appl. 2012, 173 (2012)

19. Berinde, V: Generalized coupled fixed point theorems for mixed monotone mappings in partially ordered metric spaces. Nonlinear Anal. 74, 7347-7355 (2011)

20. Hussain, N, Latif, A, Shah, MH: Coupled and tripled coincidence point results without compatibility. Fixed Point Theory Appl. 2012, 77 (2012)

21. Bhaskar, TG, Lakshmikantham, V: Fixed point theorems in partially ordered metric spaces and applications. Nonlinear Anal. 65, 1379-1393 (2006)

22. Lakshmikantham, V, Ćirić, LB: Coupled fixed point theorems for nonlinear contractions in partially ordered metric spaces. Nonlinear Anal. 70, 4341-4349 (2009)

23. Abbas, M, Khan, MA, Radenovic, S: Common coupled fixed point theorems in cone metric spaces for $W$-compatible mappings. Appl. Math. Comput. 217, 195-201 (2010)

24. Abbas, M, Khan, AR, Nazir, T: Coupled common fixed point results in two generalized metric spaces. Appl. Math. Comput. 217, 6328-6336 (2011)

25. Aydi, H, Karapınar, E, Erhan, IM: Coupled coincidence point and coupled fixed point theorems via generalized Meir-Keeler type contractions. Abstr. Appl. Anal. 2012, Article ID 781563 (2012). doi:10.1155/2012/781563

26. Choudhury, B, Kundu, A: A coupled coincidence point result in partially ordered metric spaces for compatible mappings. Nonlinear Anal. 73, 2524-2531 (2010)

27. Hung, NM, Karapınar, E, Luong, NV: Coupled coincidence point theorem in partially ordered metric spaces via implicit relation. Abstr. Appl. Anal. 2012, Article ID 796964 (2012). doi:10.1155/2012/796964

28. Hussain, N, Shah, MH, Kutbi, MA: Coupled coincidence point theorems for nonlinear contractions in partially ordered quasi-metric spaces with a Q-function. Fixed Point Theory Appl. 2011, Article ID 703938 (2011)

29. Kutbi, MA, Azam, A, Ahmad, J, Di Bari, C: Some common coupled fixed point results for generalized contraction in complex valued metric spaces. J. Appl. Math. 2013, Article ID 352927 (2013)

30. Kutbi, MA, Ahmad, J, Abbas, M, Arshad, M: Tripled coincidence and common fixed point results for two pairs of hybrid mappings. Abstr. Appl. Anal. 2014, Article ID 803729 (2014)

31. Samet, B: Coupled fixed point theorems for a generalized Meir-Keeler contraction in partially ordered metric spaces. Nonlinear Anal. 72, 4508-4517 (2010)

32. Samet, B, Vetro, C: Coupled fixed point, F-invariant set and fixed point of N-order. Ann. Funct. Anal. 1, 46-56 (2010)

33. Shatanawi, W: Partially ordered cone metric spaces and coupled fixed point results. Comput. Math. Appl. 60 , 2508-2515 (2010)

34. Alotaibi, A, Alsulami, SM: Coupled coincidence points for monotone operators in partially ordered metric spaces. Fixed Point Theory Appl. 2011, 44 (2011)

35. Luong, NV, Thuan, NX: Coupled fixed point in partially ordered metric spaces and applications. Nonlinear Anal. 74 983-992 (2011)

36. Hussain, N, Khan, AR, Agarwal, RP: Krasnosel'skii and Ky Fan type fixed point theorems in ordered Banach spaces. J. Nonlinear Convex Anal. 11(3), 475-489 (2010)

37. Parvaneh, V, Roshan, JR, Radenović, S: Existence of tripled coincidence point in ordered b-metric spaces and application to a system of integral equations. Fixed Point Theory Appl. 2013, 130 (2013)

38. Hussain, N, Nashine, HK, Kadelburg, Z, Alsulami, SM: Weakly isotone increasing mappings and endpoints in partially ordered metric spaces. J. Inequal. Appl. 2012, 232 (2012)

10.1186/1687-1812-2014-62

Cite this article as: Hussain et al.: Coupled coincidence point results for a generalized compatible pair with applications. Fixed Point Theory and Applications 2014, 2014:62 